\title{
PROTECCIÓN CONSTITUCIONAL Y CONVENCIONAL DE LAS PERSONAS CON DISCAPACIDAD COMO PRINCIPAL ESCUDO FRENTE A LOS ABUSOS DE LAS OBRAS SOCIALES
}

\author{
CONSTITUTIONAL AND CONVENTIONAL PROTECTION \\ OF PEOPLE WITH DISABILITIES AS THE MAIN SHIELD \\ AGAINST THE ABUSE OF SOCIAL WORKS
}

Ángeles María Baez

DOI: https://doi.org/10.37767/2591-3476(2020)37

Comentario a

B., P. M. C/ Administración Provincial del Seguro de Salud (APROSS)

Sala Electoral y de Competencia originaria del Tribunal Superior de Justicia

(Poder Judicial de la Provincia de Córdoba)

\author{
Disponible en \\ https://bit.ly/319LvQU
}

RESUMEN:

El presente artículo abordará el análisis de una sentencia dictada por el Tribunal Superior de Justicia de la provincia de Córdoba sobre un recurso de apelación entablando en contra de una resolución que hizo lugar a la acción de amparo impetrada por la parte actora. El Máximo Tribunal de la provincia rechazó la impugnación intentada, ordenando en el fallo lineamientos de suma relevancia para el Derecho a la Salud y especialmente para un grupo vulnerable como son las personas con discapacidad.

\begin{abstract}
The aim of this article is to analyse the decision taken by the Superior Court of Justice of the province of Córdoba on an appeal filed against a resolution, which allowed the amparo action brought by the plaintiff. The Superior court of the province rejected the attempted injunction, setting the rules which are extremely relevant guidelines for the Right to Health and especially for a vulnerable group such as people with disabilities.
\end{abstract}

1 Abogada (Universidad Nacional de Córdoba); Escribana (Universidad Siglo 21) Auxiliar del Poder Judicial de la Provincia de Córdoba, cumpliendo función de Asistente de Magistrado; Maestranda de Derecho Procesal (Universidad Siglo 21); Adscripta de la cátedra "B" de Teoría General del Proceso de la Universidad Nacional de Córdoba; miembro del proyecto de investigación "Código Procesal Civil y Comercial/ Penal de la Provincia de Córdoba" de la Secretaría de Investigación de la Universidad Siglo 21. Correo electrónico: angelesmariabaez@gmail.com. Orcid iD: https://orcid.org/0000-0003-2661-0029 
PALABRAS CLAVE: Derecho a la salud - discapacidad - amparo - cobertura integral - obras sociales.

KEY WORDS: Right to health - disability - protection - comprehensive coverage - social works.

\section{Introducción}

En la extensión de este trabajo analizaremos el fallo “B. P. M. C/ ADMINISTRACIÓN PROVINCIAL DEL SEGURO DE SALUD (APROSS) - AMPARO - RECURSO DE APELACIÓN" dictado el cuatro de octubre de 2019 por el Tribunal Superior de Justicia de la Provincia de Córdoba. En la resolución el Máximo Tribunal rechaza el recurso de apelación deducido por la demandada APROSS en contra de la sentencia dictada por la Cámara de Apelaciones con competencia Contencioso Administrativo de Segunda Nominación de la ciudad de Río Cuarto, que hizo lugar al amparo de salud promovido por la parte actora.

Consideramos que estamos frente a una resolución ejemplar, que nos permite entender que la justicia es efectiva cuando resuelve partiendo de un detallado análisis de las circunstancias particulares del caso, con la finalidad de dotar de equidad a la solución y poniendo especial énfasis en la protección constitucional y convencional para, de este modo, arribar a una resolución fundada, que garantice el efectivo goce de los derechos de los grupos vulnerables, acreedores de una especial protección por parte del Estado.

\section{Derecho a la salud: su recepción constitucional y convencional}

El derecho a la salud es un derecho fundamental personalísimo que tiene toda persona por su condición de tal. La Organización Mundial de la Salud define a la salud como “un estado de completo bienestar físico, mental y social, y no solamente la ausencia de afecciones o enfermedades". Podríamos decir que "se trata de una definición holística y progresista que considera a la salud, ya no sólo como un fenómeno meramente somático y psicológico, sino también social. La salud se considera así como un fenómeno complejo que debe ser abordado a través de la interdisciplinariedad, pues para poder comprenderla en su multidimensionalidad es necesario que concurran diversas disciplinas que interactúen y se integren entre sí" (Alcántara Moreno, 2008, p. 100).

En ese orden de ideas, observamos el abandono, con acierto, de una visión de salud considerada solamente desde el punto de vista médico y biológico, para desplazarlo de este modo a un concepto mucho más amplio que involucre a la economía, el derecho, la ciencia política, la ecología, la antropología, entre otras. En efecto, si trasladamos la noción al ámbito del derecho diremos que comprende el derecho al disfrute del más alto nivel posible de salud física y mental, incluidas las condiciones de vida saludables y de servicios de salud disponibles, accesibles y de buena calidad (Monasterio Figueroa, 2018).

Cabe recordar que en nuestro país la protección de la vida y la integridad psicofísica de la persona humana, se enfatizó a partir de la reforma de la Constitución Nacional de 1994. Entre los numerosos avances, el art. 75 inc. 22 otorgó jerarquía constitucional a los tratados internacionales sobre derechos humanos, afianzando la protección del derecho a la vida y dignidad humana. En esta materia corresponde al Estado asumir las obligaciones fundamentales y garantizar el derecho a la salud y velar por su cumplimiento. Conforme surge del art. 75, inc. 23 de la Carta Magna, el Estado Nacional asume la calidad de garante de los derechos reconocidos por los Tratados Internacionales. 
En el ámbito provincial, la Constitución de Córdoba en su artículo 27 señala que "los discapacitados tienen derecho a obtener una protección integral del Estado que abarque la prevención, asistencia, rehabilitación, educación, capacitación, inserción en la vida social, y a la promoción de políticas tendientes a la toma de conciencia de la sociedad respecto de los deberes de solidaridad". Podemos deducir del citado artículo que el Estado provincial también reconoce su obligación de brindar protección integral a las personas con discapacidad, por lo que promueve políticas sociales que fomenten la solidaridad. Se advierte, en consonancia con lo expuesto precedentemente, que la protección es amplia y abarca no sólo lo tendiente a la asistencia médica, sino también lo necesario para lograr la inserción en la sociedad de forma digna (Mensa González, 2006, p. 55).

En lo que respecta a las leyes nacionales, cabe destacar de forma particular la Ley 22.431, del año 1981, que establece un sistema de protección integral de las personas con discapacidad. Por otro lado, la Ley 24.901, del año 1997, instituye un sistema de prestaciones básicas en habilitación y rehabilitación integral a favor de las personas con discapacidad, con el objeto de brindarles una cobertura integral a sus necesidades y requerimientos.

Desde el plano internacional, el art 10 de la Convención sobre los Derechos de las Personas con Discapacidad señala: "Los Estados Partes reafirman el derecho inherente a la vida de todos los seres humanos y adoptarán todas las medidas necesarias para garantizar el goce efectivo de ese derecho por las personas con discapacidad en igualdad de condiciones con las demás." Por su parte el art. 25 de la Convención establece: "Los Estados Partes reconocen que las personas con discapacidad tienen derecho a gozar del más alto nivel posible de salud sin discriminación por motivos de discapacidad. Los Estados Partes adoptarán las medidas pertinentes para asegurar el acceso de las personas con discapacidad a servicios de salud que tengan en cuenta las cuestiones de género, incluida la rehabilitación relacionada con la salud...".

Dentro de este contexto normativo, la Corte Suprema de Justicia de la Nación también ha tenido numerosos pronunciamientos en relación al derecho a la salud. Recalcamos la importancia de la solución del caso que nos convoca en armonía con los parámetros fijados por el más Alto Tribunal de nuestro país que tiene dicho que el derecho a la salud está íntimamente relacionado con el derecho a la vida (CSJN, 01/06/2000, "Asociación Benghalensis y otras c. Estado Nacional", LL, 2001-B, 126) y, además, que este último es "el primer derecho natural de la persona humana preexistente a toda legislación positiva que, obviamente, resulta reconocido y garantizado por la Constitución Nacional y las leyes"(CSJN, 06/11/1980, "Saguir y Dib, Claudia Graciela s/ autorización", LL, 1981-A, 401; CSJN, 27/1/1987; CSJN, 27/02/1987, "Cisilotto, María del Carmen Baricalla de c. Estado Nacional (Ministerio de Salud y Acción Social)", LL, 1987-B, 311; CSJN, 05/03/2003, "Portal de Belen - Asociación Civil Sin Fines de Lucro c. Ministerio de Salud y Acción Social de la Nación s/ amparo", LL, 2002-B, 520).

\section{Reseña del caso}

La parte actora interpuso acción de amparo con la finalidad de que la Administración Provincial de Seguro de Salud (APROSS) -obra social a la cual estaba afiliada- proceda a reincorporarla al seguro de salud, atento haber procedido a desafiliarla sin previo aviso, incluso cuando la accionante continuaba pagando el arancel correspondiente. A la petición se suma la especial situación de la actora, una joven de veintiún años que padece fibrosis quística y posee certificado de discapacidad en razón de su enfermedad. Cabe 
resaltar asimismo que la peticionante se encontraba afiliada como beneficiaria indirecta del seguro de salud contratado por su madre.

La Cámara de Apelaciones con competencia Contencioso Administrativo de Segunda Nominación de la ciudad de Rio Cuarto acogió favorablemente la vía intentada por la actora, hizo lugar al amparo deducido y emplazó a la demandada APROSS para que proceda a su reincorporación al seguro de salud. Para adoptar tal decisión, repasó el contexto normativo aplicable en el presente caso, los términos de la Ley $N^{\circ} 9277$, que conceptualiza las diversas categorías de afiliados admitidos por APROSS y establece el régimen jurídico vigente para cada uno de ellos; y los lineamientos de la Resolución $N^{\circ} 50 / 16$, invocada por la demandada para rechazar la afiliación de la amparista. Consideró que resultan aplicables a la cuestión sometida a estudio los principios consagrados en la Ley de Defensa del Consumidor y concluyó que la demandada cercenó los derechos constitucionales de la actora a la salud y a la vida.

El pronunciamiento fue impugnado por parte de la demandada APROSS, elevándose la causa al Tribunal Superior de Justicia con motivo del recurso de apelación interpuesto. La parte recurrente esbozó una alongada serie de agravios, de los cuales puede advertirse que los mismos consisten en una mera crítica a la resolución impugnada y una discrepancia con lo decidido en la instancia anterior, sin prestar atención a las circunstancias fácticas acreditadas en la causa. La demandada cuestiona puntualmente la normativa aplicada al resolver, aduciendo que se ha omitido considerar la legislación provincial a la cual su representada debe someter su actuación.

Por su parte, la actora solicita el rechazo de los agravios de la impugnante y hace saber que nunca dejó de afrontar la obligación de pago que se encontraba a su cargo, la que se realizaba de manera conjunta con el pago de la cuota de su madre, quien es la afiliada titular.

El Máximo Tribunal de la Provincia de Córdoba resolvió rechazar el recurso de apelación interpuesto por la demandada APROSS y emplazarla para que proceda a la reincorporación de la actora al seguro de salud, como beneficiaria indirecta a cargo de su madre, sin período de carencia alguno.

\section{Análisis del decisorio y consideraciones al respecto}

Resulta relevante realizar en este punto un análisis de la normativa aplicada por el Tribunal al resolver. Debemos destacar el extenso y detallado estudio efectuado por el Superior Tribunal de la Provincia, del marco jurídico normativo Constitucional y Convencional que regula el Derecho a la Vida y consecuentemente el Derecho a la Salud.

Ahora bien, específicamente la cuestión a decidir giraba en torno a determinar si la parte demandada había obrado con arbitrariedad o ilegalidad manifiesta al registrar la baja afiliatoria de la actora bajo el argumento de haber alcanzado la edad de 21 años, y posteriormente rechazar la posibilidad de su afiliación voluntaria por haber presentado la solicitud fuera del plazo reglamentado.

Previo al estudio de la normativa que regula específicamente la actuación de la obra social demandada, debemos reparar en el criterio de interpretación de los hechos aplicado por el Superior Tribunal de Justicia la Provincia de Córdoba. En el considerando número séptimo de la resolución, luego de fijar el tema a decidir el Tribunal precisó: "el examen 
de cualquier caso en el que esté de por medio la salud y, con ello, el derecho a la vida de las personas, debe partir necesariamente de un pormenorizado análisis de las circunstancias vitales particulares que subyacen al planteo a los fines de dotar de equidad a la solución que se procure, por cuanto lo justo judicial es lo que, acorde a derecho, resulta prudente y razonable en ese caso en particular y no a cualquier otro". Creemos que esta aclaración efectuada por el Tribunal es de vital importancia, pues expone en sus líneas su razonamiento jurídico, su criterio de interpretación y el alcance del derecho a la salud al momento de dictar la resolución.

Debe destacarse asimismo que en el caso bajo estudio, más allá de haber considerado la doctrina, jurisprudencia, normativa constitucional, convencional y legal en relación al derecho a la salud de las personas con discapacidad, el tribunal realizó un detallado análisis de las normas bajo las cuales la demandada rige su actuación, - la Ley 9277 y de la Resolución N0050/16- e invocadas por la misma para denegar la solicitud de la actora para acceder a la reafiliación. Del estudio de la normativa se advirtió que desde el punto de vista fáctico y jurídico no podía hacerse lugar al planteo de la parte impugnante.

Repasaremos a continuación los artículos relevantes de esa legislación para entender la solución arribada por el Tribunal: El art. 5 de la ley 9277 describe los tipos de afiliaciones, distinguiendo por un lado los afiliados obligatorios de los afiliados voluntarios, de acuerdo a la modalidad de su incorporación. A su vez, la normativa establece que los afiliados pueden ser directos o indirectos, siendo los primeros quienes resulten titulares del beneficio e indirectos quienes accedan a la cobertura por intermedio de un afiliado directo. Trasladando estos conceptos al caso de marras, podemos decir que la accionante de los presentes autos se encontraba como afiliada indirecta de su madre quien es afiliada voluntaria directa de Apross.

Ahora bien, lo relevante es que de la lectura de la norma podemos advertir que la defensa deducida por la parte impugnante, fundada en la aplicación de la Ley 9277 (la cual fue analizada en primera y ulterior instancia), que consistía en afirmar que la actora presentó en forma extemporánea la solicitud de reafiliación, no encuentra asidero legal alguno, como así tampoco la Resolución del Directorio N 0050/16 que rechaza la reafilación de la actora.

En consonancia con lo analizado podemos decir que el contenido de la Resolución emitida por el Directorio resulta arbitraria e ilegal. Para fundamentar esta afirmación basta con observar los artículos de la ley a la que hemos hecho referencia.

El artículo 8 clasifica el universo de afiliados voluntarios directos según la modalidad de su incorporación, distinguiendo entre quienes lo hacen de forma colectiva, es decir a través de una entidad determinada y legalmente constituida que adhiere conjuntamente a APROSS (inc. a), de quienes se incorporan de manera individual (inc. b).

De la lectura del artículo se colige que, una vez incorporados, los afiliados voluntarios directos de APROSS, como es el caso de la madre de la parte actora, independientemente de la modalidad de su incorporación, gozan de los mismos derechos y obligaciones que los afiliados obligatorios directos. Surge asimismo que tal igualdad, se encuentra sujeta a tres excepciones, una de las cuales es la restricción inicial y no permanente de prestaciones determinadas establecidas por el Directorio. Respecto de ésta, establece que no serán aplicables a quienes hayan sido afiliados obligatorios (directos o indirectos) 
durante un plazo igual o mayor de un (1) año corrido inmediato anterior a la solicitud de incorporación como afiliado voluntario directo, "siempre y cuando se haya formalizado tal solicitud dentro de los sesenta (60) días corridos contados a partir de la baja como Afiliados Obligatorios".

De este modo y a la luz de la normativa citada se deduce que el plazo de sesenta días invocado por la demandada, como único argumento para rechazar la afiliación, se encuentra establecido en la ley 9277, pero para un supuesto totalmente distinto al invocado por el Directorio de la accionada, es decir que no guarda relación ni punto de conexión alguno con la situación fáctica planteada en el caso bajo anatema.

Por otro costado, en relación al argumento alegado por la impugnante en cuanto a que la actora había cumplido la mayoría de edad al momento de ser dada de baja de la obra social, cabe destacar que el artículo 7 de la normativa citada individualiza quiénes serán considerados integrantes del grupo familiar primario a los fines de proceder a su incorporación obligatoria como beneficiarios indirectos de APROSS. En tal sentido determina que "Son Beneficiarios Obligatorios Indirectos...: d) Los hijos e hijas solteros mayores de edad y hasta los veintiséis (26) años que cursen estudios regulares oficialmente reconocidos y que estén a cargo del Afiliado Obligatorio Directo" (art. 7, Ley N 9277). Ello así, surge que la actora pertenecía, al grupo de afiliados obligatorios indirectos cuya cobertura de salud la accionada se encontraba obligada a cumplir, toda vez que, más allá de haber cumplido la edad de veintiún años, se encontraba a cargo de su madre quien es afiliada voluntaria directa y estaba cursando estudios regulares oficialmente reconocidos, circunstancia acreditada en autos.

Del análisis efectuado a la Ley 9277 podemos advertir, al igual que lo hizo el Tribunal, que la demandada al dar de baja la afiliación de la actora por haber cumplido la edad de veintiún años, aplicó la legislación de manera arbitraria y fragmentada y que tal proceder resultó ilegal. En esa inteligencia, resulta pertinente valorar la actitud de la demandada APROSS quien además de su actuar deliberado, era conocedora de la situación particular de la actora que posee certificado de discapacidad por el diagnóstico de fibrosis quística, y no obstante ello ordenó la baja afiliatoria y posteriormente desestimó el pedido de reafiliación. A todo lo expuesto debe agregarse además, la falta de pruebas por parte de la impugnante tendientes a acreditar los extremos invocados.

Estimamos que el Tribunal ponderó todas las circunstancias fácticas y jurídicas bajo la óptica del razonamiento y criterio de interpretación precedentemente aludido para arribar a una justa solución, que resulta ejemplar y didáctica para comprender el alcance del derecho a la salud y el especial tratamiento que debe otorgarse a los casos en los que el mismo podría verse cercenado.

\section{Reflexión final}

Luego del recorrido efectuado podemos decir que la resolución analizada nos permite subrayar una serie de aspectos a considerar. En primer lugar, destacar la solución arribada tanto por la Cámara Contencioso Administrativa como por el Tribunal Superior de Justicia que sentenciaron teniendo en miras la perspectiva de vulnerabilidad de una persona con discapacidad y brindando la protección adecuada en el caso concreto.

Debemos resaltar, asimismo, la labor realizada por el sentenciante en el sentido de ha- 
ber establecido claramente el criterio de interpretación de los hechos en aquellos casos donde se encuentre involucrado el derecho a la salud, y siempre teniendo en cuenta las circunstancias particulares del caso. Destacamos el amplio tratamiento por parte del Tribunal del plexo normativo aplicable en la materia, el haberse expedido en relación al alcance del derecho a la salud a través de referencias jurisprudenciales, doctrinales y legales. La sentencia analizada realiza un gran aporte a la jurisprudencia en materia de salud.

En relación a la actitud asumida por APROSS, nada cabe agregar a esta definición dada por el Tribunal: "...ha incurrido en una decisión voluntarista, primero al dar de baja a la actora como beneficiaria obligatoria a cargo de su madre, y luego, al rechazar la afiliación solicitada, en tanto pretendió crear una regla aplicable al caso concreto extrayendo parcelas y fragmentos de la legislación y reglamentación vigente apropiadas para llegar a la solución pretendida pero completamente alejada del contexto fáctico sobre la cual debía resolver."

La salud es un derecho humano fundamental, irrenunciable y resulta necesario protegerlo ya que configura la base esencial para poder gozar del resto de los derechos. Es por ello que entendemos que nada justifica que las personas con discapacidad tengan que llegar a defender ese derecho hasta instancias tan remotas, como los tribunales superemos provinciales o la Corte Suprema de Justicia de la Nación.

Afortunadamente en los últimos años, la protección del derecho a la salud se ha visto fortalecida, principalmente con la incorporación, en reforma constitucional del año 1994, de los Tratados Internacionales de Derechos Humanos. A ello se suma también la sanción del Código Civil y Comercial de la Nación, en el cual se plasma el fenómeno de la constitucionalización del derecho privado. No obstante, y pese a esta conquista en la que el Estado vela por la protección de los grupos vulnerables, aún queda mucho camino por recorrer en la materia. Es dable advertir en la actualidad una gran cantidad de amparos en materia de salud, muchos de los cuales se originan en razón de los abusos o conductas discriminatorias asumidas por las obras sociales, como es el caso que hemos analizado en este artículo.

Esta situación evidencia la dificultad para trasladar a la realidad el cumplimiento de las garantías y deberes por parte de los actores responsables y, en definitiva, de la sociedad toda en busca del bien común. Varios de los reclamos referidos al derecho a la salud de las personas con discapacidad devela que el problema no radica tanto en la discusión del alcance del derecho ni en la falta de producción legislativa sino en la falta de cumplimiento de las obligaciones que estas generan en cabeza de las provincias, de las obras sociales, empresas de medicina prepaga, o de la administración nacional (Clérico, 2009).

En suma, entendemos que el derecho a la salud debe constituirse no sólo como un reconocimiento legislativo y jurisprudencial sino como un derecho fundamental que, por su relación con la vida de las personas, se pueda visibilizar como efectivo en la sociedad actual. 


\section{REFERENCIAS BIBLIOGRÁFICAS}

- Alcántara Moreno, Gustavo (2008), La definición de salud de la Organización Mundial de la Salud y la interdisciplinariedad, Sapiens. Revista Universitaria de Investigación. 9(1), 93107. ISSN: 1317-5815. Disponible en: https://www.redalyc.org/pdf/410/41011135004.pdf - Monasterio Figueroa, Rodrigo (2018), Acceso a la salud como forma de integración social de las personas con discapacidad, Cita Online: AR/DOC/1316/2018

- Mensa González, Andrea (2006), Constitución de la Provincia de Córdoba Anotada, Alveroni, Córdoba.

- Clérico, María Laura (2009), El derecho a la salud de las personas con discapacidad: ¿el argumento del federalismo como acelerador o como freno, Cita Online: AR/DOC/1936/2009 